\title{
Introduction to Gender in Language Education
}

\author{
Handoyo Puji Widodo ${ }^{1}$ (D) . Tariq Elyas ${ }^{1}$ \\ Published online: 19 May 2020 \\ (c) Springer Science+Business Media, LLC, part of Springer Nature 2020
}

\begin{abstract}
This introduction to the special issue provides a snapshot of why gender in our lives and in language education matters. We also summarize each of the articles featured in this special issue. Inspired by the growing body of research into gender and language education across the globe, directions for future studies in this area are also highlighted. We contend that any educational practices and artifacts are ideologically and institutionally gender-laden. We hope that this special issue can be the point of departure for exploring more gender issues at different levels of language education (e.g., schools, universities, and virtually-mediated education spaces) in the pursuit of gender responsiveness.
\end{abstract}

Keywords Gender · Gender identity and ideology · Gender representation · Gender responsiveness $\cdot$ Language education

\section{Rationale}

In our lives, we cannot avoid gender discourses and practices. We normatively think, act, and behave according to our gender roles or identities. For example, it is widely acknowledged that women (girls) are responsible for doing domestic chores (e.g., cooking, cleaning, doing dishes, sweeping) while men (boys) do physically-oriented things, such as gardening, repairing a car, or fixing up a bike. Beyond a male-female gender identity dichotomy, globalized social, cultural, political, and economic changes exert influence upon gender ideologies (ways of thinking, acting, behaving), relationships (social identities), and practices. Equally important, globalized sociocultural, political and economic geographies shape how men (boys) and women (girls) from different ethnic, racial, and religious groups or communities of practice manifest their gender identities as part of fluid social identities (Pavlenko and Piller

Handoyo Puji Widodo

handoyopw@yahoo.com

Tariq Elyas

telyas@kau.edu.sa

1 King Abdulaziz University (KAU), Jeddah, Saudi Arabia 
2008). These geographies also shape or create the privilege and marginalization of particular groups of people or communities of practices within a wider society. In other words, socio-economic conditions, sociocultural norms, values, and ideologies contribute to gendered privilege and marginalization. The following cases show how sociocultural norms and ideologies affect gender roles in Indonesia and Saudi Arabia, for example.

In traditional Javanese (a major ethnic group in Indonesia) society where a traditionally patriarchal belief/norm is strongly entrenched, women (girls) have to be able to cook in order to demonstrate their womanly or girly identity. In this societal context, women (girls) have to serve family members or guests, such as preparing foods and serving guests drinks and cookies. This social practice has changed to some extent; men can cook at home, or a man can help his couple or mother prepare food. Another example of how global socio-economic changes affect gender roles that men and women play in contemporary Javanese (Indonesia) is due to gender equity (Setyono 2018). For instance, women have a wide range of opportunities to pursue their careers as a pilot, an engineer, or a doctor. This social movement forces labor markets to provide Indonesian citizens with more access to gender-equal occupations. In another socio-economic context, women may have to play a role as breadwinners in order to support family economy, share family's financial responsibilities, or to improve the quality of life in terms of education and health, for instance.

Traditional Saudi society is not much different from its Javanese counterparts. Historically, Saudi women (girls) have been portrayed as being domestic queens (Goddess), and men (boys) have been socially assigned as providers and protectors (Titans) of the family. The identity of Saudi women (girls) is situated in a private sphere (e.g., staying at home, doing domestic chores) while the identity of Saudi men (boys) are socio-spatially connected to a public sphere (e.g., hanging out with other men). But, social roles and customs in the Kingdom of Saudi Arabia with its 2030 vision are changing, and gender roles are being revisited. Gender equity and equality rights in all aspects of everyday lives are commonly practiced. Over the last 50 years, Saudi women's position has changed significantly in many cases (Elyas et al. 2020). For instance, there have been increased opportunities for women to pursue education and employment due to Saudi Arabia's social development. New educational institutions have been established for females. Women (girls) have the equal opportunity to take such majors as engineering, media studies, sciences, and several vocational courses. In the field of employment, Saudi women can serve as deans of colleges, CEOs of banks, IT specialists, doctors, photographers, and journalists among others. Saudi women have also experienced a great improvement in terms of their social rights. In 2011, King Abdullah proclaimed that women would be nominated to Majlis Al-Shura 'consultative council.' Later in 2018, King Salman announced a decree that lifted the ban on women driving and permitted females to apply for driving licenses (Elyas and AlJabri 2020). This showcases the manifestation of gender equality in the Saudi context.

Following critical linguists (e.g., Appleby 2009; Cameron 2005; Pavlenko and Piller 2008; Sunderland 2000), we posit that gender should be viewed as a socially modulated and dynamic system of power relations and ideologically discursive practice. This suggests that women (girls) and men (boys) play uniquely different 
gender roles. Throughout history, society and particular communities of practice have shaped how individuals should think, act, and behave according to their gender role and identity. They serve as social agents of imposing a variety of gendering practices and ideologies about normative ways of being men (boys) and women (girls). Against this backdrop, we would like to bring up the issue of gender in language education in order to continue scholarly dialog and discussion about gender representation (identity) and genderness discourses and practices in the language education domain.

\section{Gender in Language Education}

We contend that gender representation, identities, discourses, and practices are shaped or constructed by particular sociocultural norms and ideologies intertwined with other ideologies, such as socio-institutional ideology, political ideology, religious ideology, racial ideology, socio-economic ideology, and power relations. These dimensions make gendered discourse and practices and a line of inquiry into gender in language education more dynamic, fluid, and complex. In other words, they contribute to (re)constructing genderness in language education from a critical perspective. Therefore, gender in language education should be viewed as two entities: a site of social practice and a line of critical inquiry.

Gender discourses and practices are inevitably inherent in the educational territory in general and in language education in particular. We define language education as an institutional space and discourse that embraces four educational practices: (1) language education policy and planning, (2) language education curricula, (3) language pedagogy and instruction, and (4) language education assessment and testing. We argue that social actors at different levels of education from primary education to tertiary education play a pivotal role in canalizing or imposing particular values (gender-related values: gender equality and gender responsiveness) through educational practices and documents (Ariyanto 2018; Sulaimani and Elyas 2018; Widodo 2018). Schools and universities are regarded as educational spaces that canalize or instil particular gender-related values due possibly to political, economic, and social forces in society and particular communities of practice. In practice, both teachers and students are producers and consumers of gendered texts that represent gendered identities, discourses, and practices.

Inadvertently or advertently, the issues of gender and genderness have seeped into educational territories, discourses, and practices. For example, policy makers may promote the inclusion of gender equity or equality in language education policy and planning documents. Language curriculum designers may put emphasis on gender issues when designing curriculum documents, such as syllabi, lesson plans, and textbooks. At a pedagogical level, teachers and teacher educators may teach gender issues in order to build a self-awareness of gender responsiveness. Another example of gender responsiveness is the use of gender-neutral language or texts in classroom interactions. Therefore, it is a must for policy makers, curriculum developers, materials writers, teachers, teacher educators, and students to build and enhance their critical awareness of gender-related issues, such as gender responsiveness, gender 
mainstreaming, gender (in)equality, and gender stereotyping. This is because teachers and teacher educators not only teach language knowledge, skills, and attitudes, but they also build students' critical awareness of particular values, such as moral values, cultural values, and gender-related values (Widodo et al. 2018). We are fully aware that whether such values may be prioritized depends on socio-institutional contexts because different countries place emphasis on particular gender-related issues, such as gender (in)equality.

Gender in language education has been a field of critical interdisciplinary inquiry. Over the past few decades, there has been a steadily growing body of research on gender and language education (Rowlett and King 2017). In some literature, in this research area, work on sexuality and language education has burgeoned. Two approaches, the discourse turn in language studies and the performative turn in gender studies to gender and sexuality in language education have informed studies into gender and sexuality in language education (Menard-Warwick et al. 2014). So far, there has been a myriad of studies into (1) gender identities and language learning situated in language classrooms and educational institutions; (2) narratives of the impact of gender and sexual identity positions upon learners' investments and agency in second language learning; and (3) the gendered experiences of teachers in the language teaching profession (Rowlett and King 2017). To continue this line of critical inquiry into gender in language education, this special issue presents what current research tells us.

\section{What Current Empirical Research into Gender and Language Education Tells the Reader}

This special issue features eight original articles written by emerging and wellestablished scholars from different countries, such as Australia, the USA, Thailand, Ghana, Hong Kong, Iran, Indonesia, Brunei Darussalam (the Philippines), and Saudi Arabia. This suggests that the special issue has successfully created scholarly discussion and debates among scholars from different geographical areas. We hope that this geographical diversity can help see diversity in views, perspectives, and ideas that enlighten us about the manifestation of gender in language education.

The contributors of this special issue reported findings that cast some light on gender issues drawing on ethnographic and single case studies, narrative inquiry, and critical discourse studies. Two articles address how gender identities affect language learning and classroom interactions and position learners in different ways together with other social identities and the discourses that surround them. Other two articles underscore the construction of teacher identities (professional identity and gender-fair language use) in the educational territory. Four articles report findings (gender representation in language textbooks and test papers) informed by critical discourse studies. In other words, the eight articles collected in this special issue attempt to contribute to a growing body of research into gender and language education.

To begin with, in Age, Gender, and Language Teacher Identity in Higher Education, Sarah Mason \& Alice Chik report a narrative study that examined the 
social construction of Japanese university teacher identities. This narrative study looks particularly into how Japanese university teachers' gender identities affected the enactment of their age identities. Drawing on in-depth interview data, Mason and Chik found that the male and female university teachers constructed their age identities differently, but the female teachers felt disadvantaged as faculty members throughout their professional lives.

In their article, Understanding Immigrant Youths' Negotiation of Racialized Masculinities in One U.S. High School, Kongji Qin and Guofang Li present an ethnographic case study of three immigrant boys' negotiation of racialized masculinities and its impact on their language learning in one U.S. ESL classroom. Grounded in intersectionality and critical race theory, the findings revealed that the immigrant boys connected their masculinity to negotiation of hyphenated selves in complex transnational and transcultural spaces where their gender identities were intersectionally constructed by racism (racialization), linguicism, homophobia, and heteronormativity that impacted upon the participants' language learning.

In response to contextually-undertheorized research on queer teachers and LGBT rights and policies, Hai Lin, Wannapa Trakulkasemsuk, and Pattamawan Zilli (When Queer Meets Teacher) reports a narrative study of a non-local English teacher working in a Thai university. Based on a life history interview, Lin, Trakulkasemsuk, and Zilli examine the construction of queer self as a professional language teacher. They reported that the participant demonstrated a socially fluid queer identity which was not affected by the dominant discourse of heteronormativity. This empirical evidence suggests that a queer teacher is a professional agent since the discourse of queer as professional is (re)constructed and normalized at work.

To continue empirical scholarship into the use of anti-sexist language, in her article, Exploring the Adoption of gender-fair Spanish alternatives in School domains, Benedicta Lomotey examines the usage of gender-fair language among the members of the academic community situated in the teaching of Spanish as a foreign language at a Ghanaian public university. Informed by a corpus and discourse analysis of audio recorded classroom lessons, examination papers, WhatsApp chats and electronic messages, Lomotey found that the majority of the participants for both the native and non-native participants had similar opinions on the issues of sex-exclusiveness and invisibility, but they had opposing opinions regarding the charge for gender inequity or gender imbalance.

A study by Jackie Lee and Vahid Mahmoudi-Gahrouei (Gender Representation in Instructional Materials) looks into how gender is represented in the "English for School Series, Prospect", newly published by the Iranian Ministry of Education. The findings showed that the textbook authors demonstrated some gender consciousness, such as the use of gender-neutral vocabulary and fair distribution of male and female dialogue texts despite the prevalence of low female visibility due to the inclusion of the Islamic culture of male predominance. Drawing on interviews with school teachers, Lee and Mahmoudi-Gahrouei showed that the school teachers encouraged textbook revision or change in order to promote gender equality in education.

To respond to under-explored scholarship into gender representation in assessment papers, in their article, An Analysis of Gender Representation in Territorywide System Assessment English Language Papers for Primary School Students 
in Hong Kong, Chi Cheung Ruby Yang and Tsoi Lam Yan investigate how males and females are represented in Territory-wide System Assessment (TSA), a territory-level assessment administered in Hong Kong. The data of this study showed that males and females are equally represented in the written texts and in the visuals. The textual analysis revealed that females are depicted as involving in occupational roles more visibly than their male counterparts in both the written texts and the visuals. Despite this, females are portrayed as being responsible for family matters, and the marital status of females is still differentiated by the use of either Miss or Mrs.

In the similar vein, Reni Lestariyana, Handoyo Widodo, and Urip Sulistiyo (Female Representation in Mandated English Language Textbooks Used in Indonesian Junior High Schools) examine two government-mandated language teaching textbooks used in Indonesian junior schools. They explore the representation of female characters in the textbooks situated in such social contexts as family, occupations, school participation and achievement, and hobbies and interests. They found that to some extent, the textbook authors showed their gender responsiveness (e.g., women are socially assigned as a career woman (surgeon) while they still promote the traditionally patriarchal belief (e.g., females take a traditionally feminine communal role). Lestariyana, Widodo, and Sulistiyo also found that female-dominated stereotypes in the areas of school participation and achievement as well as hobbies still exist in the textbooks.

In their article, Gender (In)equality in English Textbooks in the Philippines, Eulalia Curaming and Rommel Curaming investigate the representations of gender relations in a popular English textbook series used in primary schools in the Philippines, which is a highly-ranked country in global gender equality indices. They found that the persistence of male dominance still exists in the textbook. This may reflect the enduring gender gap in the country, especially in economic and political domains. This empirical indicates that gender inequality is still deeply rooted in language education in a highly-ranked country in global gender equality indices.

It is important to emphasize that the inquiry of gender issues in foreign and second language education (e.g., English and Spanish) is important in order to interrogate whether particular foreign and second language curriculum practices (e.g., teaching and assessment) impose particular ideological values, such as gender responsiveness or gender stereotyping of which both teachers and learners may be unaware. In most cases, foreign and second languages can be an institutionalized agent of reinforcing what gender-related values society holds. For example, the value of being responsible for household chores or the patriarchal belief (men as breadwinners and women as homemakers) is reinforced in Indonesian English textbooks although native speakers of English in Anglophone contexts and other English-speaking countries may not believe in nor hold this belief. Another reason for addressing gender in foreign and second language education is that any language cannot be divorced from genderness and culture. For example, both German and Arabic are influenced by gender-laden use of language. As another example, international textbook writers may portray women as working individuals who are not obliged to perform household chores. In high culture contexts, such as in Indonesia and Saudi Arabia, although women pursue their career, they have to carry out household chores, such as doing a laundry/dishes and cooking. In other words, foreign and second language education can play an agentive role in reinforcing 
or imposing particular ideological values, such as gender-laden values. This because foreign and second language education not only equip learners with language knowledge and skills but also help them build or enhance their awareness of particular values.

\section{Directions for Future Scholarship and Research into Gender and Language Education}

We acknowledge that this special issue includes limited research into gender and language education. It is important to set out more research agendas in this research area. More critical ethnographic case studies should be undertaken to investigate educational practices and documents that showcase gender identities and representation(s). There should be more critical discourse studies informed by critical interdisciplinary theories that examine gender representation in language curriculum documents and textbooks as well as assessment documents at primary, secondary, and tertiary education levels. Classroom-based studies will need to be carried out in order to examine how students work on gendered texts and how teachers talk about gender issues in language classrooms or virtually-mediated learning spaces. More empirical research agendas should be geared towards documenting teacher-student and student-student interactions as they reflect gender discourses and identities. There should be empirical reports on innovative ways of integrating critical understandings of gender into language education.

As the contributors of this special issue recommend, more gender research into age and identity among professional teachers/practitioners should be undertaken because age and gender identity contribute to the construction of gendered and racialized professional identity among female and male professionals in the educational territory. More applications of rigorous and fresh theories (e.g., intersectionality and critical race theory) should be adopted to examine the complexity and intersectionality of immigrant/transnational youth's masculinity/femininity negotiation by considering racism, homophobia and linguicism. In terms of textbook evaluation, although there is still a long journey to reform school textbooks to establish egalitarian gender norms (gender responsiveness), there should be intervention-based studies that can help school and university teachers build and enhance their critical awareness of gender issues because they play a more active role in the promotion of gender equality, sensitivity, and responsiveness among the younger generation. This kind of research can be directed to provide pedagogical interventions to equip textbook writers and school teachers as agents of change with critical gender knowledge and skills. As Chi Cheung Ruby Yang and Tsoi Lam Yan suggest in this special issue, critical investigation into language testing documents which remain rare will need to be undertaken.

\section{Closing Remarks}

The articles featured in this special issue explore some of the myriad ways how gender representation, discourses, and practices are manifested in language education. Together, they offer insightful directions for research interrogating the link between 
gender and language education because language education discourses and practices cannot be divorced from gender issues. Gender issues in language education are interesting to discuss and investigate. We hope that this collection could be a catalyst for continuing critical scholarship and research into gender in language education. We hope that more studies will report gender issues in less-taught foreign and local or indigenous languages in different contexts. We hope that readers find the eight articles featured in this special issue as engaging and thoughtful as we do. It is our sincerest hope that critical scholars will pave new avenues for scholarship on gender and language education.

Acknowledgements We would like to express our sincerest gratitude to Roberto Refinetti, Editor-inChief at Sexuality \& Culture, and the editorial staff at Springer for supporting this special issue through all stages of its progress.

Funding This study was not funded by any parties.

\section{Compliance with Ethical Standards}

Conflict of interest The authors declare that they have no conflict of interest.

Ethical Approval This article does not contain any studies with human participants performed by any of the authors.

Informed Consent Informed consent was not applicable to this editorial piece.

\section{References}

Appleby, R. (2009). The spatial politics of gender in EAP classroom practice. Journal of English for Academic Purposes, 8(2), 100-110. https://doi.org/10.1016/j.jeap.2008.09.004.

Ariyanto, S. (2018). A portrait of gender bias in the prescribed Indonesian ELT textbook for junior high school students. Sexuality and Culture, 22, 1054-1076. https://doi.org/10.1007/s12119-018-9512-8.

Cameron, D. (2005). Language, gender, and sexuality: Current issues and new directions. Applied Linguistics, 26(4), 482-502. https://doi.org/10.1093/applin/ami027.

Elyas, T., \& AlJabri, A. (2020). Representations of Western newspapers on Saudi male's guardianship system \& women's freedom to travel: A critical discourse analysis. Contemporary Issues in Middle East, 7(3), 1-19. https://doi.org/10.1177/2347798920921977.

Elyas, T., Al-Zahrani, K., Mujaddadi, A., \& Almohammadi, A. (2020). The representation(s) of Saudi women pre-driving era on local newspapers and magazines: A critical discourse analysis. British Journal of Middle Eastern Studies, 2(2), 1-20. https://doi.org/10.1080/13530194.2020.1744427.

Menard-Warwick, J., Mori, M., \& Williams, S. (2014). Language and gender in educational contexts. In S. Ehrlich, M. Meyerhoff, \& J. Holmes (Eds.), The handbook of language, gender, and sexuality (pp. 471-490). Hoboken: Wiley.

Pavlenko, A., \& Piller, I. (2008). Language education and gender. In N. H. Hornberger (Ed.), Encyclopedia of language and education. Boston, MA: Springer.

Rowlett, B., \& King, B. W. (2017). Language education, gender, and sexuality. In T. McCarty \& S. May (Eds.), Language policy and political issues in education. Encyclopedia of language and education (3rd ed.). Cham: Springer.

Setyono, B. (2018). The portrayal of women in nationally-endorsed English as a foreign language (EFL) textbooks for senior high school students in Indonesia. Sexuality and Culture, 22, 1077-1093. https ://doi.org/10.1007/s12119-018-9526-2.

Sulaimani, A., \& Elyas, T. (2018). A glocalized or globalized edition? Contextualizing gender representation in EFL textbooks in Saudi Arabia: A critical discourse analysis Perspective. In A. Selvi \& N. 
Rudolph (Eds.), Conceptual shifts and contextualized practices in education for glocal interaction: Issues and implications (pp. 55-76). Singapore: Springer.

Sunderland, J. (2000). Issues of language and gender in second and foreign language education. Language Teaching, 33(4), 203-223. https://doi.org/10.1017/S0261444800015688.

Widodo, H. P. (2018). A critical micro-semiotic analysis of values depicted in the Indonesian Ministry of National Education-endorsed secondary school English textbook. In H. P. Widodo, L. V. Canh, M. R. G. Perfecto, \& A. Buripakdi (Eds.), Situating moral and cultural values in ELT materials: The Southeast Asian context (pp. 131-152). Cham: Springer.

Widodo, H. P., Canh, L. V., Perfecto, M. R. G., \& Buripakdi, A. (Eds.). (2018). Situating moral and cultural values in ELT Materials: The Southeast Asian context. Cham: Springer.

Publisher's Note Springer Nature remains neutral with regard to jurisdictional claims in published maps and institutional affiliations. 